\title{
Endocannabinoids, endocannabinoid-like molecules and their precursors in human small intestinal lumen and plasma: does diet affect them?
}

\author{
Silvia Tagliamonte ${ }^{1} \cdot$ Chris I. R. Gill ${ }^{2} \cdot$ L. Kirsty Pourshahidi ${ }^{2} \cdot$ Mary M. Slevin $^{2} \cdot$ Ruth K. Price $^{2} \cdot$ Rosalia Ferracane $^{1}$. \\ Roger Lawther ${ }^{3} \cdot$ Gloria O'Connor $^{3} \cdot$ Paola Vitaglione $^{1}$ (i)
}

Received: 22 June 2020 / Accepted: 24 September 2020 / Published online: 26 October 2020

(C) The Author(s) 2020

\begin{abstract}
Purpose To determine the small intestinal concentration of endocannabinoids (ECs), $N$-acylethanolamines (NAEs) and their precursors $N$-acylphosphatidylethanolamines (NAPEs) in humans. To identify relationships between those concentrations and habitual diet composition as well as individual inflammatory status.

Methods An observational study was performed involving 35 participants with an ileostomy (18W/17M, aged 18-70 years, BMI $17-40 \mathrm{~kg} / \mathrm{m}^{2}$ ). Overnight fasting samples of ileal fluid and plasma were collected and ECs, NAEs and NAPEs concentrations were determined by LC-HRMS. Dietary data were estimated from self-reported 4-day food diaries.

Results Regarding ECs, $N$-arachidonoylethanolamide (AEA) was not detected in ileal fluids while 2-arachidonoylglycerol (2-AG) was identified in samples from two participants with a maximum concentration of $129.3 \mu \mathrm{g} / \mathrm{mL}$. In contrast, mean plasma concentration of AEA was $2.1 \pm 0.06 \mathrm{ng} / \mathrm{mL}$ and $2-\mathrm{AG}$ was $4.9 \pm 1.05 \mathrm{ng} / \mathrm{mL}$. NAEs concentrations were in the range $0.72-17.6 \mu \mathrm{g} / \mathrm{mL}$ in ileal fluids and $0.014-0.039 \mu \mathrm{g} / \mathrm{mL}$ in plasma. NAPEs concentrations were in the range $0.3-71.5 \mu \mathrm{g} /$ $\mathrm{mL}$ in ileal fluids and $0.19-1.24 \mu \mathrm{g} / \mathrm{mL}$ in plasma being more abundant in participants with obesity than normal weight and overweight. Significant correlations between the concentrations of AEA, OEA and LEA in biological fluids with habitual energy or fat intakes were identified. Plasma PEA positively correlated with serum C-reactive protein.

Conclusion We quantified ECs, NAEs and NAPEs in the intestinal lumen. Fat and energy intake may influence plasma and intestinal concentrations of these compounds. The luminal concentrations reported would allow modulation of the homeostatic control of food intake via activation of GPR119 receptors located on the gastro-intestinal mucosa.
\end{abstract}

Clinical trial registry number and website NCT04143139; www.clinicaltrials.gov.

Keywords Lipid mediators $\cdot$ Nutrient sensing $\cdot$ Ileal fluids $\cdot$ Gastrointestinal receptors $\cdot N$-acylethanolamines $\cdot$ Ileostomists

\begin{tabular}{lll} 
& \multicolumn{2}{l}{ Abbreviations } \\
& 2-AG & 2-Arachidonylglycerol \\
& AA & Arachidonic acid \\
\hline $\begin{array}{l}\text { Electronic supplementary material The online version of this } \\
\text { article (https://doi.org/10.1007/s00394-020-02398-8) contains }\end{array}$ & AEA & Anandamide \\
supplementary material, which is available to authorized users. & AEAd8 & Anandamide-d8 \\
\hline $\begin{array}{l}\text { Paola Vitaglione } \\
\text { paola.vitaglione@ unina.it }\end{array}$ & ALA & $\alpha$-Linolenic acid \\
$\begin{array}{l}\text { Department of Agricultural Sciences, University of Naples } \\
\text { "Federico II", Via Università 100, 80055 Portici, NA, Italy }\end{array}$ & CRP & Cannabinoid receptor-1 \\
$\begin{array}{l}\text { Nutrition Innovation Centre for Food and Health (NICHE), } \\
\text { School of Biomedical Sciences, Ulster University, Coleraine, }\end{array}$ & DHA & Docosaexaenoic acid \\
UK & EPA & Docosapentaenoic acid \\
$\begin{array}{l}\text { Altnagelvin Area Hospital, Western Health and Social Care } \\
\text { Trust, Glenshane Road, Londonderry, UK }\end{array}$ & FAAH & Endocannabinoids \\
\end{tabular}




$\begin{array}{ll}\text { GLP-1 } & \text { Glucagon-like peptide 1 } \\ \text { GPCRs } & \begin{array}{l}\text { G-protein-coupled receptors } \\ \text { Linoleic acid }\end{array} \\ \text { LC-HRMS } & \begin{array}{l}\text { Liquid chromatography-high-resolution } \\ \text { mass spectrometry }\end{array} \\ \text { LEA } & \begin{array}{l}\text { Linoleoylethanolamide } \\ \text { Monounsaturated fatty acids }\end{array} \\ \text { MUFA } & \begin{array}{l}N \text {-Acylethanolamine-hydrolyzing acid } \\ \text { amidase }\end{array} \\ \text { NAAA } & N \text {-Acylethanolamines } \\ \text { NAPE-PLD } & N \text {-Acyl-phosphatidylethanolamine-specific } \\ & \text { phospholipase D } \\ \text { NAPEs } & N \text {-Acylphosphatidylethanolamines } \\ \text { OEA } & \text { Oleoylethanolamide } \\ \text { PEA } & \text { Palmitoylethanolamide } \\ \text { PAEE } & \text { Physical activity energy expenditure } \\ \text { PPAR- } \alpha & \text { Peroxisome proliferator-activated receptor } \\ \text { PUFA } & \text { Polyunsaturated fatty acids } \\ \text { RPAQ } & \text { Recent physical activity questionnaire } \\ \text { SFA } & \text { Saturated fatty acids }\end{array}$

\section{Introduction}

Endocannabinoids (ECs) and their structural congeners $\mathrm{N}$-acylethanolamines (NAEs), also known as "endocannabinoid-like molecules", are endogenous lipid mediators involved in a wide range of biological pathways regulating appetite, nutrient metabolism, energy balance and inflammation [1, 2]. ECs include 2-arachidonoylglycerol (2-AG) and $N$-arachidonoylethanolamide (AEA) [3] while the most studied NAEs are $N$-oleoylethanolamide (OEA), $N$-palmitoylethanolamide (PEA), $N$-linoleoylethanolamide (LEA) and $N$-stearoylethanolamide (SEA) $[4,5]$.

Circulating NAEs and AEA as well as 2-AG are formed from membrane precursors, such as $\mathrm{N}$-acylphosphatidylethanolamines (NAPEs) and diacylglycerol, through the activity of NAPE-specific phospholipase D (NAPE-PLD) and diacylglycerol lipase (DAGL), respectively. Other enzymes hydrolyse NAEs and ECs to fatty acids and ethanolamines [6-8].

ECs elicit their biological activities through the cannabinoid type 1 (CB1) and type 2 (CB2) receptors which are located mainly in the brain but also in peripheral tissues, such as the intestine, liver, skeletal muscle, vascular endothelium, reproductive tissues, and tissues of the immune system [5]. NAEs regulate food intake, glucose homeostasis and inflammation through activation of $\mathrm{G}$ protein-coupled receptors (GPCRs), peroxisome proliferator-activated receptors (PPAR- $\alpha$ ), and transient receptor vanilloid potential receptors (TRVP) [9-11]. Some of these receptors are located on cells lining in the gastro-intestinal tract (GIT). For example, GPR119 is expressed on cells in the stomach, small intestine and colon [12] and, upon NAE-mediated activation, it elicits the secretion of the insulin-regulating peptides, glucagon-like peptide 1 (GLP-1) and glucosedependent insulinotropic peptide (GIP) $[13,14]$. PPAR- $\alpha$ is expressed in the small intestine, kidneys, liver, heart and brown adipose tissue and increases satiety through its ligand OEA [15-17]. In contrast, 2-AG and AEA stimulate food intake through the $\mathrm{CB} 1$ receptors [18].

Mounting evidence in subjects with inflammatory bowel disease and obesity indicates that circulating ECs are key mediators in the interplay between gut, microbiota and metabolic health [19-23]. Moreover, plasma ECs and NAEs are considered biomarkers of white adipose tissue distribution and insulin resistance in obesity [24-32] and, as NAPEs, they are tightly connected with diet, especially dietary fat [1] but also proteins [33, 34].

On the other hand, ECs, NAEs, and NAPEs are present in several foods [35], they increased in saliva upon food mastication in humans [36, 37] and the direct injections of NAPEs in the duodenum reduced food intake in mice [38]. Altogether, this evidence raised the question of whether the luminal content of ECs, NAEs, and NAPEs may be sufficient to elicit biological effects through the receptors located in the GIT.

Therefore, we determined the concentrations of ECs, NAEs and NAPEs in ileal fluids and plasma collected during an observational study in participants with ileostomy and investigated their relationship with habitual macronutrient and energy intake as well as with individual inflammatory status.

\section{Methods}

\section{Study design}

This study is part of an observational study (16/NI/0267) whose primary outcome was the assessment of bone mineral density (by Dual-energy X-ray absorptiometry) in ileostomy patients. Secondary outcomes included: anthropometric measurements, habitual diet, blood lipid profile, blood inflammatory marker, blood polyunsaturated fatty acids, blood and ileal endocannabinoids, and physical activity. The study was conducted with the prior approval of the Office for Research Ethics Committees Northern Ireland (ORECNI), the University of Ulster Ethical Committee and with the informed consent of participants and in accordance with the Declaration of Helsinki. The trial was registered at www.clinicaltrials.gov (NCT04143139). Participants (male and non-pregnant females) recruited to the study were aged 18-70 years and had previously undergone an ileostomy and were $2+$ years post-operative at time of recruitment. 
Participants were excluded if they were outside the desired age range or had their surgical procedure $<2$ years before.

Following an overnight fast, the participants visited the clinic of Ulster University in Coleraine (UK) and provided ileal fluid sample and blood samples.

All participants provided questionnaires including a 4-day estimated food diary to establish habitual dietary intake completed within \pm 14 days of sampling, subsequently analysed using Nutritics Nutrition Analysis Software. A validated Recent Physical Activity Questionnaire (RPAQ) [39] was also completed by each participant to capture self-reported habitual activity levels at home, work and in leisure time. The total physical activity energy expenditure (PAEE) was estimated by summing up the individual energy expenditure due to each activity domain (home, work and recreational).

\section{Preparation of biological samples}

To avoid handling bias with ileal fluids, we used methodologies consistent with precautions as described in Karu et al. [40] for metabolomic analysis in faeces. The ileal fluid samples were collected and processed within $30 \mathrm{~min}$ as described in Mc Dougall et al. [41]. In brief, volumes and $\mathrm{pH}$ values of the ileal fluids were recorded, before dilution with ice-cold distilled water as required, dependent on the viscosity, and before the fluid was homogenized in a chilled Waring blender for $30 \mathrm{~s}$.

Fasting blood samples were collected by venipuncture into serum separator and EDTA-containing tubes. To avoid EDTA blood samples handling bias that may lead to ex vivo biotransformation of monitored compounds, we used recommendations of Gurke and co-workers [42]. All EDTA blood samples were kept chilled/on ice before processing. Plasma samples were prepared by centrifugation at $3000 \mathrm{rpm}$ for 15 min at $4{ }^{\circ} \mathrm{C}$ and within 15 min of collection. Serum samples were prepared by allowing blood to clot for $30 \mathrm{~min}$ at room temperature, then centrifugation at $3000 \mathrm{rpm}$ for 15 min at $4{ }^{\circ} \mathrm{C}$.

Once prepared, ileal fluids, serum and plasma samples were aliquoted and immediately frozen at $-80{ }^{\circ} \mathrm{C}$. All samples were kept frozen at Ulster University according to Human Tissue Act (HTA) standards until further analysis.

\section{Extraction of ECs, NAEs and NAPEs from ileal and plasma samples}

Simultaneous extractions of ECs, NAEs and NAPEs from ileal fluids and plasma were performed using the method by Bligh and Dyer with brief modifications [43]. All samples were thawed in the fridge at $4{ }^{\circ} \mathrm{C}$ before extraction and samples were kept chilled on ice during the specific extraction procedures [42]. The ileal fluids samples were diluted prior the extraction to enhance the efficiency of solvent extraction as previously reported in faeces [40, 44].

Ileal fluids $(100 \mu \mathrm{L})$ previously diluted 1:10 with distilled water and plasma samples $(500 \mu \mathrm{L})$ were added to $50 \mu \mathrm{L}$ of the internal standard $200 \mathrm{ng} / \mathrm{mL}$ solution of Arachidonoylethanolamide d8 (AEA d8) (Cayman Chemical, Ann Arbor, MI). A volume of $1.5 \mathrm{~mL}$ of $\mathrm{CHCl}_{3} / \mathrm{CH}_{3} \mathrm{OH}(2: 1 \mathrm{v} / \mathrm{v})$ was added to the sample that was vortexed for $20 \mathrm{~s}$ and centrifuged at $14,800 \mathrm{rpm}$ for $10 \mathrm{~min}$ at $4{ }^{\circ} \mathrm{C}$. Then, the supernatant was collected in a glass tube and the pellet was extracted with $\mathrm{CHCl}_{3} / \mathrm{CH}_{3} \mathrm{OH}(2: 1)$ twice. $\mathrm{KCl} 0.07 \mathrm{M}(2 \mathrm{~mL})$ was added to the collected phase and the lower layer (chloroform phase) was evaporated under nitrogen flow and reconstituted in $100 \mu \mathrm{L}$ acetonitrile/isopropanol/water (60:35:5) prior the LC-HRMS analysis.

The extraction recovery was $86 \%$ in ileal fluids and $71 \%$ in plasma samples.

\section{Liquid chromatography-high-resolution mass spectrometry (LC-HRMS) analysis}

LC-HRMS analysis was performed by adapting the method by Gregory et al. [44]. Data were collected using an Accela U-HPLC system consisting of a quaternary pump and a thermostated autosampler $\left(10^{\circ} \mathrm{C}\right)$ coupled to an Exactive Orbitrap MS provided with a heated electrospray interface (HESI) (Thermo Fisher Scientific, San Jose, CA). The compounds were separated on a Kinetex $2.6 \mu$ C18 $100 \AA$ A column $(100 \mathrm{~mm} \times 2.1 \mathrm{~mm})$ (Phenomenex, Torrance, CA) with setting temperature at $45^{\circ} \mathrm{C}$ and eluted by a linear gradient of a 40:60 water/acetonitrile mixture ( $5 \mathrm{mM}$ ammonium formate $0.1 \%$ formic acid) (solvent A) and 90:10 isopropanol/ acetonitrile $(5 \mathrm{mM}$ ammonium formate and $0.1 \%$ formic acid) (solvent B) with a flow rate of $200 \mu \mathrm{L} / \mathrm{min}$ and volume injection of $10 \mu \mathrm{L}$. According to Gregory et al., eluting gradient was set as follows: $32 \%$ B from 0 to $1.5 \mathrm{~min}, 32-45 \%$ B from 1.5 to $4 \mathrm{~min}, 45-52 \%$ B from 4 to $5 \mathrm{~min}, 52-58 \%$ B from 5 to $8 \mathrm{~min}, 58-66 \%$ B from 8 to $11 \mathrm{~min}, 66-70 \% \mathrm{~B}$ from 11 to $14 \mathrm{~min}, 70-75 \% \mathrm{~B}$ from 14 to $18 \mathrm{~min}, 75-97 \% \mathrm{~B}$ from 18 to $21 \mathrm{~min}$ and kept at $97 \%$ B until 25 min [44]. MS detection was performed in positive- and negative-ion modes in the $m / z$ 120-1200 mass range: spray voltage was $3.5 \mathrm{kV}$ (positive mode) and $3.0 \mathrm{kV}$ (negative mode), capillary voltage $30 \mathrm{~V}$, heater temperature $300{ }^{\circ} \mathrm{C}$, capillary temperature at $350{ }^{\circ} \mathrm{C}$, sheath gas 35 and auxiliary gas 15 arbitrary units, respectively.

Compounds were identified and quantified against authentic standards using exact mass value up to the fifth decimal digit ( \pm 5 ppm mass tolerance). ECs (2-AG; AEA; AEAd8) and NAEs (OEA, LEA, PEA) standards were purchased from Cayman (Cayman Chemical, Ann Arbor, MI). $\mathrm{N}$-arachidonoylphosphatidylethanolamine standard was purchased from Santa Cruz Biotechnology (Santa Cruz Biotechnology, 
Inc., USA). SEA was expressed as equivalents of PEA. NAPEs were found in the chromatographic region between 19 and 23 min and were detected in negative-ion mode as $[\mathrm{M}-\mathrm{H}]^{-}$. In the chromatographic region between 6 and 9 min, the NAEs were detected in positive-ion mode as $[\mathrm{M}+\mathrm{H}]^{+}$. Supplementary Table 1 reports the molecular formula, theoretical and experimental mass, the mass accuracy and the retention time of identified compounds. The limit of detection (LoD) and limit of quantification (LoQ) of the identified molecules are reported in Supplementary Table 2.

\section{Biochemical analysis}

Circulating lipid profiles (serum triglycerides, total and HDL cholesterol) were quantified on the iLab 650 Clinical Chemistry auto-analyzer (Instrumentation Laboratory, Massachusetts, USA) using a commercially available assay. LDL cholesterol was calculated using the Friedewald formula [45]. Serum C-reactive protein (CRP) was measured at the clinical chemistry department of St James' Hospital Dublin.

Total lipid was extracted from serum according to a modified version of Folch et al. [46] where chloroform and methanol were used as the extracting solvents in a 2:1 ratio, with $250 \mu \mathrm{L}$ of plasma extracted in $5 \mathrm{~mL}$ of extracting solvents [47], the wash solution was $3: 47: 48$ (chloroform:methanol:water). Fatty acid methyl esters were detected and quantified for six key polyunsaturated fatty acids (PUFA) - linoleic acid (LA), arachidonic acid (AA), $\alpha$-linolenic acid (ALA), eicosapentaenoic acid (EPA), docosapentaenoic acid (DPA) and docosahexaenoic acid (DHA) using the gold-standard technique of gas chromatography-mass spectrometry (7890A-5975C; Agilent) using heptadecanoic acid (C17:0) as the internal standard, as previously described [47]. In brief, to a $250 \mu \mathrm{L}$ plasma sample, $18 \mu \mathrm{L}$ internal standard (heptadecanoic acid (C17:0)) was added and then chloroform:methanol (2:1) to a final volume of $5 \mathrm{~mL}$. The solution was vigorously mixed, $1 \mathrm{~mL} \mathrm{DDH}_{2} \mathrm{O}$ added, then centrifuged at $2500 \mathrm{~g}$ for $5 \mathrm{~min}$. The upper layer was discarded, the remaining solution washed twice with chloroform:methanol:water $(3: 48: 47)$ and the sample filtered, then evaporated to dryness (at $70{ }^{\circ} \mathrm{C}$, under nitrogen). Toluene $(100 \mu \mathrm{L})$ and borontrifluoride methanol $(500 \mu \mathrm{L})$ were added and the solution maintained at $100{ }^{\circ} \mathrm{C}$ for $1 \mathrm{~h}$. Subsequently, $250 \mu \mathrm{L}$ of hexane and $800 \mu \mathrm{L} \mathrm{DDH} \mathrm{DD}_{2} \mathrm{O}$ were added to the cooled sample and mixed. The supernatant was then removed and evaporated to dryness (at $50{ }^{\circ} \mathrm{C}$, under nitrogen). Extractions were reconstituted in $180 \mu \mathrm{L}$ ethyl acetate before analysis on GC/MS which was completed in split mode (split ratio 1:20), with a BPX70 capillary GC column (SGE Analytical Science) (length $30 \mathrm{~m}$, internal diameter $250 \mu \mathrm{m}$ and film thickness $0.25 \mu \mathrm{m}$ ), using helium as the carrier gas (constant flow at $1.0 \mathrm{~mL} / \mathrm{min}$ ). Samples were injected using an automatic liquid sampler (ALS) (injection volume $1 \mu \mathrm{L}$ ) at a temperature of $130{ }^{\circ} \mathrm{C}$, this was then ramped at $15{ }^{\circ} \mathrm{C} / \mathrm{min}$ to $200{ }^{\circ} \mathrm{C}$ and then at $30{ }^{\circ} \mathrm{C} / \mathrm{min}$ to $250{ }^{\circ} \mathrm{C}$ where it was held for $5 \mathrm{~min}$. Mass Spectrometry was operated in positive-ion mode using an electron ionisation (EI) source. The mass range was set to $50-500 \mathrm{Da}$ and acquisition was performed by Total Ion Chromatogram (TIC). We identified the individual PUFA-LA, AA, ALA, EPA, DPA and DHA - by their retention time and corresponding qualifier ions with reference to those of commercially available fatty acid standards (Sigma Aldrich, UK). These were quantified by use of an internal standard, heptadecanoic acid (C17:0) (Sigma Aldrich, UK) and corresponding PUFA target ions (quantifiers). For the purpose of this paper, we have defined: Total PUFA as the sum of LA, ALA, AA, EPA, DPA, DHA; n-3 fatty acids as the sum of ALA, EPA, DPA and DHA; $n-6$ fatty acids as the sum of LA and AA; $n-6: n-3$ ratio as the ratio between $n-6$ and n- 3 fatty acids.

\section{Anthropometric measurements}

Height and weight were measured using standardized procedures to determine Body Mass Index (BMI, $\mathrm{kg} / \mathrm{m}^{2}$ ). Standing height $(\mathrm{cm})$ was measured to the nearest $0.5 \mathrm{~cm}$ using a calibrated stadiometer (SECA, Model 220, Germany). Body weight $(\mathrm{kg})$ was recorded without footwear or heavy clothing and was measured to the nearest $0.1 \mathrm{~kg}$ using portable scales (Seca; Brosch Direct Ltd, Peterborough, UK). Participants were considered with normal weight when the BMI was in the range $18.5-24.9 \mathrm{~kg} / \mathrm{m}^{2}$, with overweight when the BMI was in the range $25.0-29.9 \mathrm{~kg} / \mathrm{m}^{2}$ and with obesity when the BMI was higher than $30 \mathrm{~kg} / \mathrm{m}^{2}$.

\section{Statistical analysis}

Statistical analyses were performed in $\mathrm{R}$ version 3.6.0. After being checked for normality, significantly skewed variables were transformed in $\ln (x)$ with $k$ values. For those that showed a normal distribution at the Kolmogorov-Smirnov test, Student's $t$ test was performed to check differences between sexes. One-way ANOVA and Bonferroni adjustment for multiple comparisons were performed to check differences between compounds in the overall population. For the variables which did not show a normal distribution after logarithmic transformation, a non-parametric Mann-Whitney test was performed. Two-tailed $\mathrm{P}$ values lower than 0.05 were considered significantly different. To test correlations between concentrations of NAPEs, NAEs and ECs in biological fluids with the dietary intake, all variables were transformed in $\ln (x)$ and a Pearson correlation test was performed to check the best model to fit the curve. In all cases, logarithmic model was selected and results obtained were reported. Data are expressed as means \pm SEM. 


\section{Results}

\section{Study participants}

The participant flow is shown in Fig. 1. 35 participants with ileostomy were recruited and completed the study. The characteristics of the participants including general information and anthropometry, serum lipids, PUFA and CRP as well as the mean dosages of each type of medication taken by 27 subjects, are reported in Table 1. Differences between sexes were found for height and weight that were higher, as well as serum HDL-cholesterol concentrations that were lower, in men than women. The participants had a mean BMI of $26.9 \pm 0.9 \mathrm{~kg} / \mathrm{m}^{2}$, specifically there was 1 subject (1 man) who was underweight, 11 subjects ( 8 women and 3 men) with normal weight (NW), 12 (7 women and 5 men) with overweight (OW) and 11 ( 3 women and 8 men) with obesity (OB). Compared to NW, OB showed higher triglycerides $(1.19 \pm 0.15 \mathrm{mmol} / \mathrm{L}$ vs $0.6 \pm 0.06 \mathrm{mmol} / \mathrm{L}, p=0.002)$ and lower HDL-cholesterol concentrations $(0.99 \pm 0.08 \mathrm{mmol} / \mathrm{L}$ vs $1.32 \pm 0.06 \mathrm{mmol} / \mathrm{L}, p=0.013)$. No significant difference between BMI classes for general characteristics and CRP was observed.

\section{Concentration of ECs, NAEs and NAPEs in ileal fluids}

Figure 2 shows the ileal concentrations of monitored NAEs and NAPEs in overall population and some significant differences between sexes and BMI classes.

Mean concentrations of NAEs and NAPEs were not significantly different $(3346.94 \pm 561.39 \mathrm{ng} / \mathrm{mL}$ vs $4896.99 \pm 2043.01 \mathrm{ng} / \mathrm{mL}$ ).

LEA was the most abundant NAE and it was, like OEA, significantly higher in men than women while PEA concentration was significantly higher in OW than NW.

No differences between sexes in ileal concentrations of PEA, SEA and NAPEs or between BMI classes in ileal LEA, OEA, SEA and NAPEs concentrations were found (Supplementary Fig. 1).

\section{Plasma concentration of ECs, NAEs and NAPEs}

Figure 3 shows the plasma concentrations of all monitored compounds in the population. In contrast to ileal fluids, AEA and 2-AG were frequently detected and in similar concentrations in plasma. PEA was the most abundant NAE followed by SEA, and similar concentration of OEA and LEA.

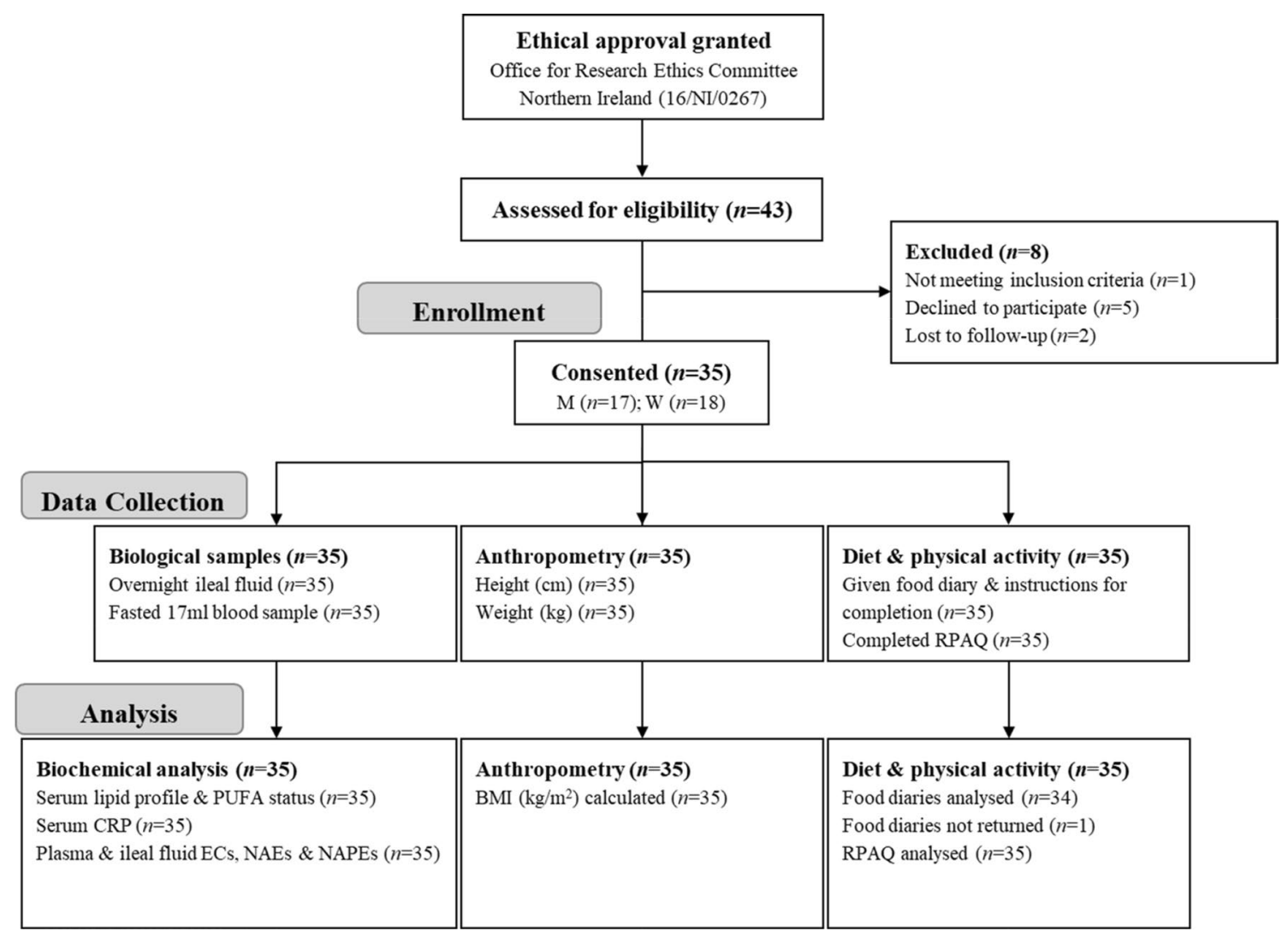

Fig. 1 Participants flow 
Table 1 Characteristics of the study participants with ileostomy

\begin{tabular}{|c|c|c|c|c|}
\hline & All $(n=35)$ & Women $(n=18)$ & $\operatorname{Men}(n=17)$ & $p$ value $^{\mathrm{a}}$ \\
\hline \multicolumn{5}{|l|}{ General characteristics and anthropometry } \\
\hline Age (years) & $51.1 \pm 2.4$ & $50.8 \pm 3.8$ & $51.4 \pm 3.0$ & 0.898 \\
\hline Height $(\mathrm{cm})$ & $168.1 \pm 1.3$ & $162.7 \pm 1.2$ & $173.9 \pm 1.4$ & $<0.001$ \\
\hline Weight (kg) & $76.4 \pm 3.1$ & $68.3 \pm 3.1$ & $85.0 \pm 4.9$ & 0.006 \\
\hline $\mathrm{BMI}\left(\mathrm{kg} / \mathrm{m}^{2}\right)$ & $26.9 \pm 0.9$ & $25.9 \pm 1.2$ & $28.0 \pm 1.5$ & 0.266 \\
\hline Ileal fluids $\mathrm{pH}$ & $6.1 \pm 0.1$ & $6.1 \pm 0.1$ & $6.1 \pm 0.1$ & 0.908 \\
\hline Ileal fluids net weight (g) & $234.6 \pm 15.9$ & $229.1 \pm 15.4$ & $240.5 \pm 28.9$ & 0.732 \\
\hline PA energy expenditure $(\text { MET h/day })^{\mathrm{b}}$ & $21.6 \pm 3.0$ & $16.2 \pm 1.8$ & $27.3 \pm 5.8$ & 0.087 \\
\hline \multicolumn{5}{|l|}{ Serum lipids } \\
\hline Triglycerides (mmol/L) & $0.92 \pm 0.08$ & $0.92 \pm 0.12$ & $0.92 \pm 0.12$ & 0.840 \\
\hline Total cholesterol (TC, mmol/L) & $3.52 \pm 0.14$ & $3.69 \pm 0.19$ & $3.33 \pm 0.19$ & 0.190 \\
\hline LDL-cholesterol (mmol/L) & $1.94 \pm 0.12$ & $2.02 \pm 0.17$ & $1.86 \pm 0.16$ & 0.509 \\
\hline HDL-cholesterol (mmol/L) & $1.16 \pm 0.05$ & $1.26 \pm 0.04$ & $1.05 \pm 0.08$ & $\mathbf{0 . 0 3 0}$ \\
\hline $\mathrm{LA}(\mathrm{mg} / \mathrm{mL})$ & $1.10 \pm 0.04$ & $1.16 \pm 0.05$ & $1.04 \pm 0.05$ & 0.131 \\
\hline ALA (mg/mL) & $0.01 \pm 0.00$ & $0.01 \pm 0.00$ & $0.01 \pm 0.00$ & 0.245 \\
\hline $\mathrm{AA}(\mathrm{mg} / \mathrm{mL})$ & $0.28 \pm 0.02$ & $0.28 \pm 0.02$ & $0.27 \pm 0.02$ & 0.815 \\
\hline $\mathrm{EPA}(\mathrm{mg} / \mathrm{mL})$ & $0.01 \pm 0.00$ & $0.02 \pm 0.00$ & $0.01 \pm 0.00$ & 0.226 \\
\hline $\mathrm{DPA}(\mathrm{mg} / \mathrm{mL})$ & $0.01 \pm 0.00$ & $0.01 \pm 0.00$ & $0.01 \pm 0.00$ & 0.918 \\
\hline DHA (mg/mL) & $0.03 \pm 0.00$ & $0.04 \pm 0.01$ & $0.02 \pm 0.00$ & 0.093 \\
\hline Total PUFA $(\mathrm{mg} / \mathrm{mL})^{\mathrm{c}}$ & $1.45 \pm 0.05$ & $1.52 \pm 0.07$ & $1.37 \pm 0.07$ & 0.144 \\
\hline n-6:n-3 ratio ${ }^{d}$ & $28.67 \pm 3.15$ & $28.41 \pm 4.62$ & $28.93 \pm 4.40$ & 0.451 \\
\hline \multicolumn{5}{|l|}{ Inflammatory status } \\
\hline $\mathrm{CRP}(\mathrm{mg} / \mathrm{L})$ & $3.30 \pm 0.66$ & $3.71 \pm 1.18$ & $2.87 \pm 0.57$ & 0.719 \\
\hline \multicolumn{5}{|l|}{ Medications (mg/kg b.w./day) } \\
\hline Antihistamine $(n=5 ; 2 \mathrm{~W}, 3 \mathrm{M})$ & $0.28(0.15-0.42)$ & $0.29(0.15-0.42)$ & $0.27(0.21-0.35)$ & \\
\hline Antidiarrheal $(n=5 ; 2 \mathrm{~W}, 3 \mathrm{M})$ & $0.22(0.08-0.39)$ & $0.17(0.16-0.17)$ & $0.25(0.08-0.39)$ & \\
\hline Antihypertensive $(n=4 ; 1 \mathrm{~W}, 3 \mathrm{M})$ & $1.42(0.06-3.10)$ & 1.65 & $1.34(0.06-3.10)$ & \\
\hline Antacids $(n=7 ; 3 \mathrm{~W}, 4 \mathrm{M})$ & $0.43(0.19-0.86)$ & $0.51(0.42-0.66)$ & $0.38(0.19-0.86)$ & \\
\hline Antidepressant $(n=5 ; 2 \mathrm{~W}, 3 \mathrm{M})$ & $0.49(0.24-1.07)$ & $0.39(0.32-0.47)$ & $0.56(0.24-1.07)$ & \\
\hline Cholesterol lowering $(n=6 ; 2 \mathrm{~W}, 4 \mathrm{M})$ & $0.49(0.33-0.66)$ & $0.62(0.58-0.66)$ & $0.42(0.33-0.51)$ & \\
\hline
\end{tabular}

$B M I$ Body mass index, $P A$ physical activity, $L A$ linoleic acid, $A L A$ alpha-linolenic acid, $A A$ arachidonic acid, EPA eicosapentaenoic acid, $D P A$ docosapentaenoic acid, DHA docosahexaenoic acid, PUFA polyunsaturated fatty acids, $C R P$ C-reactive protein

Data are expressed as means \pm SEM. Medications are expressed as means (range) of dosages (mg/kg body weight/day) taken by total $(n)$ subjects; $n$ women (W), $n$ men (M)

${ }^{\mathrm{a}} p<0.05$ in bold indicates significant difference between women and men, by Student's $t$ test or Mann-Whithney test depending on data normal distribution

${ }^{\mathrm{b}}$ Self-reported data collected using a validated physical activity (PA) questionnaire [39]

${ }^{\mathrm{c}}$ Total PUFA: sum of LA, ALA, AA, EPA, DPA, DHA

${ }^{d}$ n-6:n-3 ratio: (sum of LA and AA)/(sum of ALA, EPA, DPA and DHA)

No difference in plasma NAEs between sexes and between BMI classes was observed (Supplementary Fig. 2). Contrarily, circulating levels of plasma NAPEs were higher in OB compared to NW subjects (Fig. 3).

Interestingly, positive logarithmic correlations between plasma CRP with PEA $(r=0.411, p=0.014)$ and BMI ( $r=0.363, p=0.032$ ) were found (Fig. 4). Although, subjects who took supplements had lower serum CRP concentrations than those who did not $(2.66 \pm 0.95$ and
$3.83 \pm 0.92, p=0.024$ ) (Supplementary Fig. 3), supplement consumption did not affect plasma ECs, NAEs and NAPEs concentration.

No significant association between plasma concentration of the monitored compounds and age with the exception of a negative association between AEA plasma and age in men $(r=-0.522, p=0.032)$ independently of BMI, was found. 

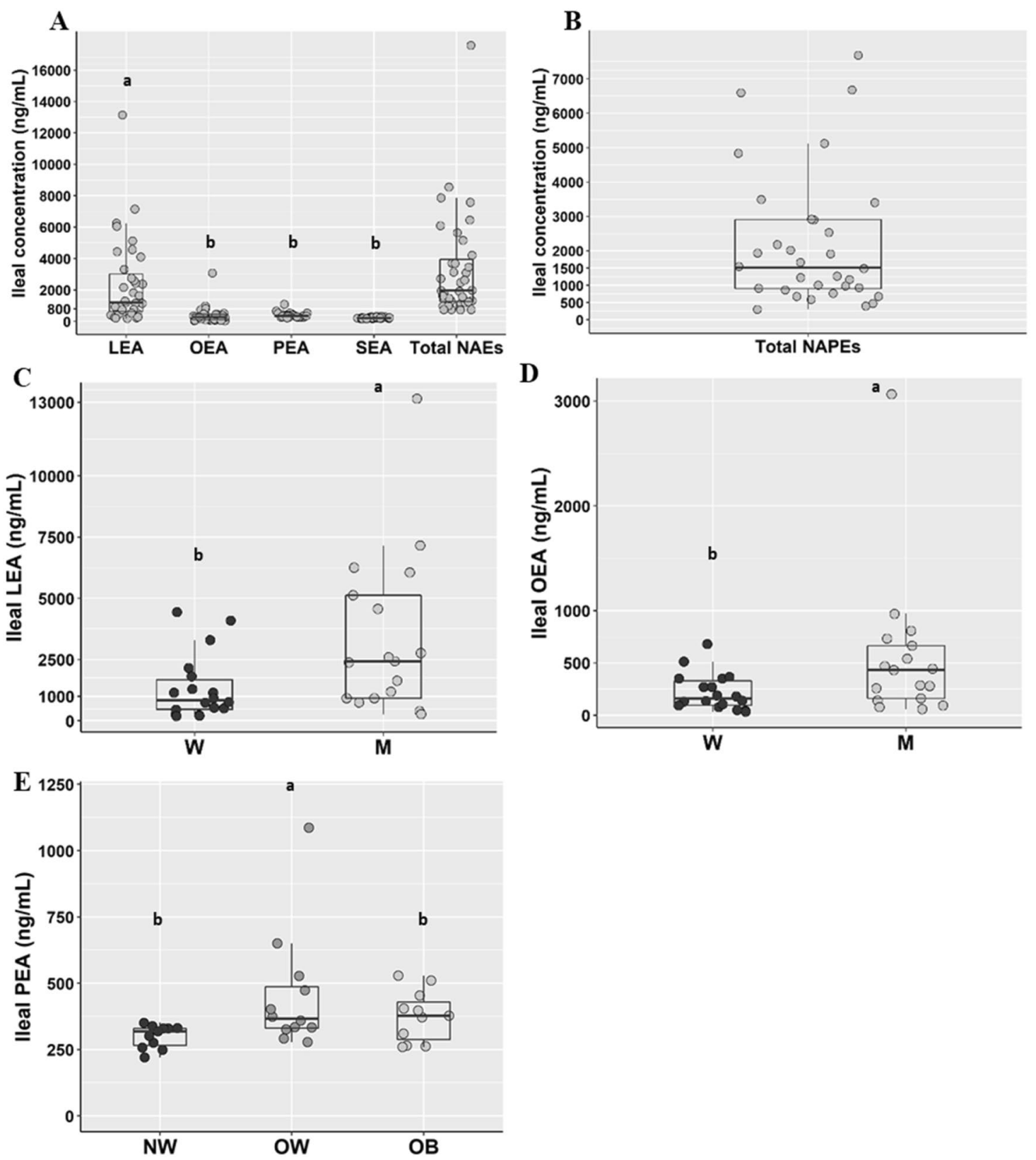

Fig. $2 \mathrm{~N}$-acylethanolamines (a) and $\mathrm{N}$-acylphosphatidylethanolamines (b) concentrations in ileal fluids from the overall population $(n=35)$, LEA (c) and OEA (d) concentrations in ileal fluids from men (M, empty dots; $n=17)$ and women (W, solid dots; $n=18)$ and PEA (e) concentrations in ileal fluids from participants with normalweight (NW; $n=11)$, overweight (OW; $n=12)$ and obesity. Different letters on the box plots indicate $p$ value $<0.05$ by One-way ANOVA

\section{Diet and correlations with plasma and ileal fluids of ECs, NAEs and NAPEs}

Table 2 shows daily energy value and macronutrient composition of diets self-reported by the participants. Women reported significantly lower energy, carbohydrate, protein and fat intakes than men but a similar repartition of energy

and Bonferroni adjustement for multiple comparisons or by Student's $t$ test. Total NAEs include the sum of LEA, OEA, PEA and SEA. LEA Linoylethanolamide, OEA oleoylethanolamide, PEA palmitoylethanolamide, SEA stearoylethanolamide, NAES $N$-acylethanolammines, NAPEs $N$-acylphosphatidylethanolamines. The box plots show the data distribution based on first quartile, median and third quartile

among macronutrients; only the \% energy from dietary fiber was higher in women than in men. Self-reported dietary intakes and plasma concentrations of PUFAs were similar between sexes (Table 1). Overall dietary intake of $n-3$ PUFAs was lower $(1.2 \pm 0.21 \mathrm{~g})$ compared to the intake of $\mathrm{n}-6$ PUFAs $(5.8 \pm 0.68 \mathrm{~g})$, reflecting a limited consumption of foods like oily fish in the cohort with only 6 out of 34 

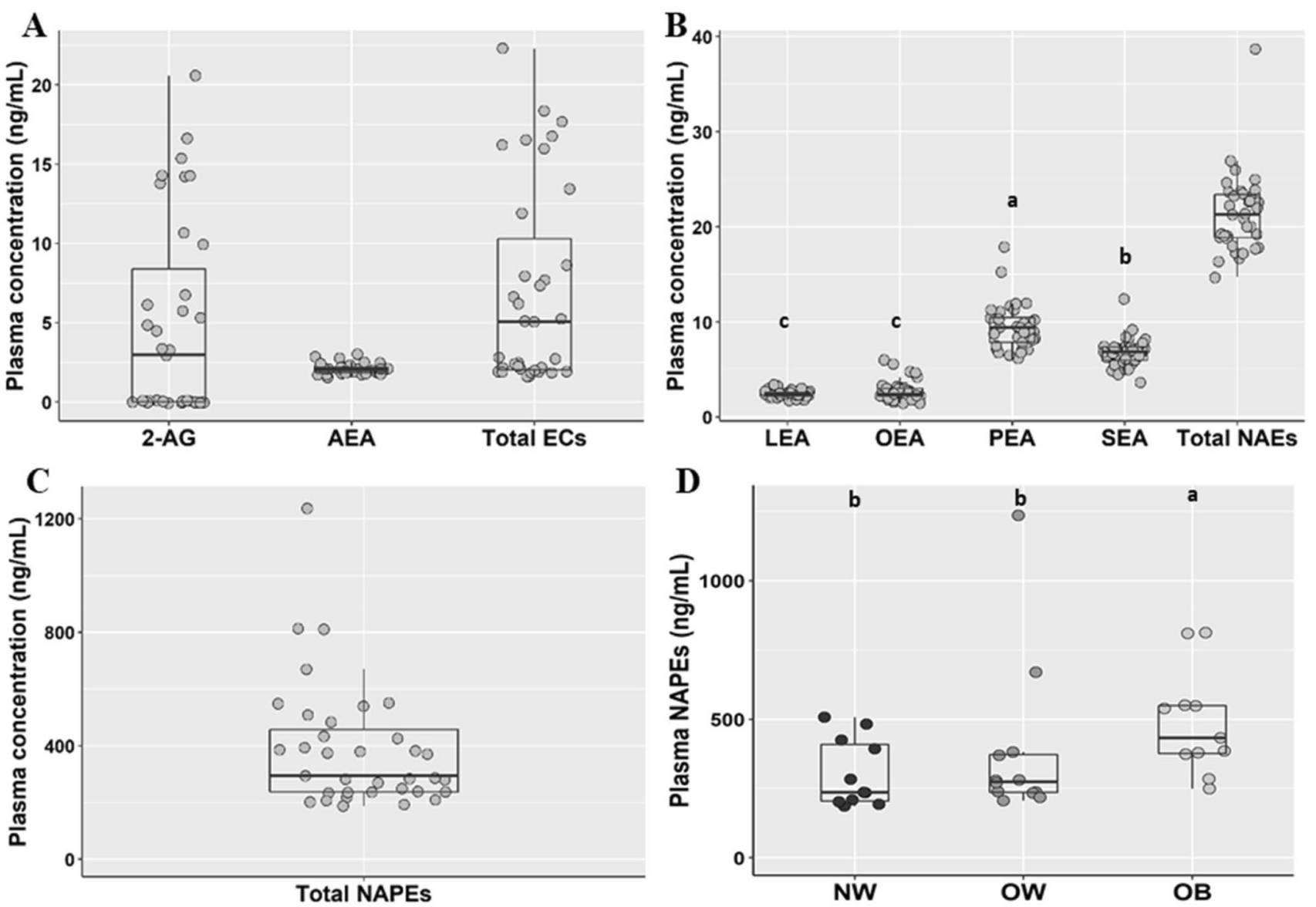

Fig. 3 Plasma Endocannabinoids (a), $N$-acylethanolammines (b) and $N$-acylphosphatidylethanolamines (c) concentrations in the overall population $(n=35)$ and $N$-acylphosphatidylethanolamines (d) plasma concentrations from participants with normalweight $(\mathrm{NW}$; $n=11$ ), overweight (OW; $n=12)$ and obesity (OB, $n=11)$. Different letters on the box plots indicate $p$ value $<0.05$ by One-way ANOVA and Bonferroni adjustement for multiple comparisons. Total ECs

participants reporting intake (group average $55 \pm 60 \mathrm{~g} /$ day) and only two consumed canned oily fish (group average $23.1 \pm 9.7 \mathrm{~g} /$ day). Whereas foods rich in n-6 PUFAs, such as chicken (22/34 participants, group average $65.7 \pm 61.2 \mathrm{~g} /$ day) and eggs (20/34 participants, group average $21.8 \mathrm{~g} \pm 12.1 \mathrm{~g} /$ day), were consumed in greater quantities and by more participants. Only nine participants consumed nuts and seed (group average $17.6 \pm 16.0 \mathrm{~g} /$ day) a rich source of MUFAs. The relative amounts $(\mathrm{g})$ of self-reported food consumption for all participants in the study are shown in Supplementary Table 3.

A logarithmic correlation analysis between ileal and plasma concentrations of ECs, NAEs and NAPEs with habitual self-reported energy and nutrient intakes, was performed. Results showed that ileal concentrations of LEA positively correlated with individual energy intake whereas plasma concentrations of LEA, OEA and AEA inversely include the sum of 2-AG and AEA; total NAEs include the sum of LEA, OEA, PEA and SEA. 2-AG 2-Arachidonoylglicerol, $A E A$ arachidonoylethanolamide, ECs endocannabinoids, $L E A$ linoylethanolamide, $O E A$ oleoylethanolamide, $P E A$ palmitoylethanolamide, $S E A$ stearoylethanolamide, NAES N-acylethanolammines, NAPES $\mathrm{N}$-acylphosphatidylethanolamines. The box plots show the data distribution based on first quartile, median and third quartile

correlated with it. Moreover, we found that ileal concentrations of LEA and OEA positively correlated with fat intake whereas plasma concentrations of LEA, OEA, and AEA were negatively correlated. Specifically, plasma concentrations of LEA and AEA negatively correlated with saturated fat intake; PEA negatively correlated with $\mathrm{n} 6, \mathrm{n} 3$ series and PUFA intake; OEA negatively correlated with PUFA and AEA with MUFA intake. Moreover ileal LEA and OEA were positively associated with saturated fat and trans fat intake. All the correlations found are detailed in Supplementary Table 4.

\section{Correlations between serum PUFA and ECs, NAEs and NAPEs}

Plasma LEA and 2-AG concentrations were negatively associated with AA while SEA was positively associated 


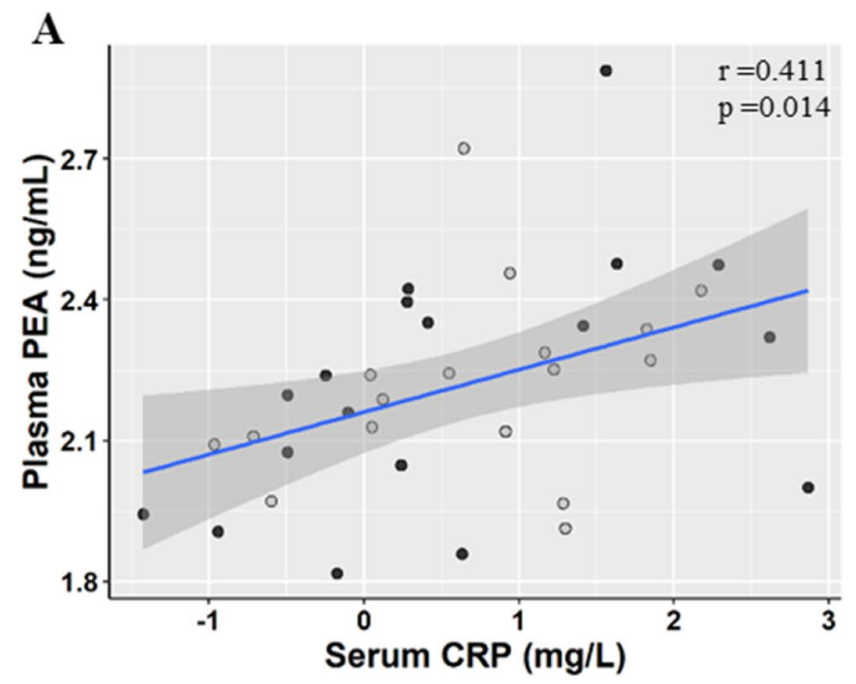

Fig. 4 Correlation between individual plasma concentrations of PEA (a), BMI (b) and individual serum CRP. Men (M, $n=17)$ are indicated with empty dots and women (W, $n=18)$ with solid dots. $\mathrm{R}$ and

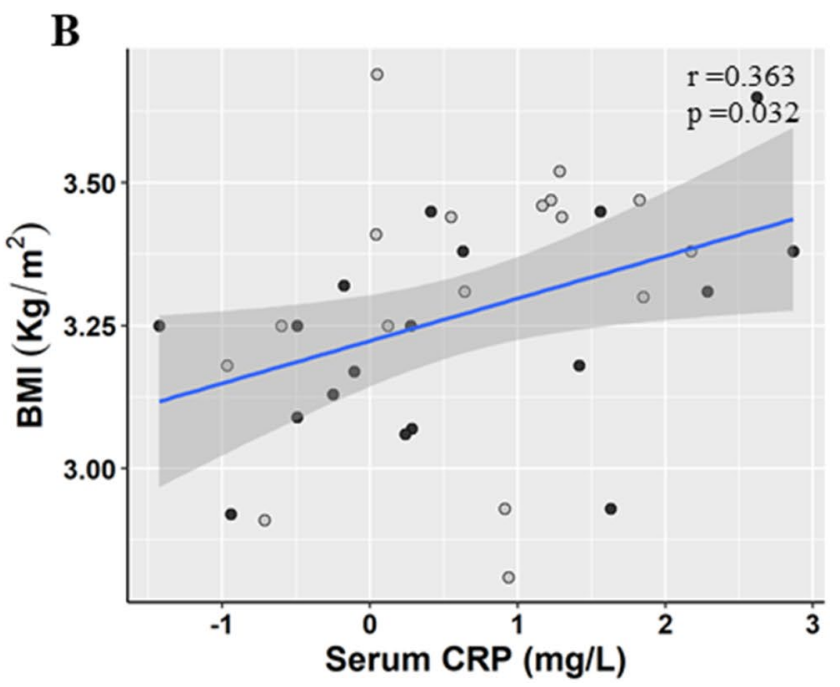

$p$ value are assessed by Pearson correlation on $\ln$ transformed variables. PEA palmitoylethanolamide, CRP C-reactive protein, BMI Body Mass Index
Table 2 Nutritional composition of habitual diets of all the study participants and by sexes

\begin{tabular}{lcccc}
\hline & All $(n=34)$ & Women $(n=18)$ & Men $(n=16)$ & $p$ value $^{\mathrm{a}}$ \\
\hline Energy (kJ kcal) & $8292.8 \pm 364.2$ & $7176.5 \pm 393.7$ & $9548.7 \pm 473.4$ & $<\mathbf{0 . 0 0 1}$ \\
& $1982.0 \pm 87.1$ & $1715.2 \pm 94.1$ & $2282.2 \pm 113.1$ & \\
Carbohydrates (g) & $221.9 \pm 9.3$ & $195.8 \pm 9.9$ & $251.3 \pm 13.0$ & $\mathbf{0 . 0 0 2}$ \\
\% Energy & $45.3 \pm 1.0$ & $46.2 \pm 1.4$ & $44.3 \pm 1.4$ & 0.334 \\
Dietary fiber (g) & $17.8 \pm 0.8$ & $17.7 \pm 1.2$ & $17.9 \pm 1.0$ & 0.914 \\
\% Energy & $1.9 \pm 0.1$ & $2.1 \pm 0.2$ & $1.6 \pm 0.1$ & $\mathbf{0 . 0 0 6}$ \\
Proteins (g) & $85.5 \pm 4.6$ & $73.0 \pm 5.4$ & $99.5 \pm 6.1$ & $\mathbf{0 . 0 0 2}$ \\
\% Energy & $17.4 \pm 0.7$ & $17.0 \pm 0.8$ & $17.9 \pm 1.2$ & 0.519 \\
Fats (g) & $79.7 \pm 5.0$ & $67.2 \pm 5.4$ & $93.7 \pm 7.4$ & $\mathbf{0 . 0 0 6}$ \\
\% Energy & $35.4 \pm 1.1$ & $34.7 \pm 1.6$ & $36.2 \pm 1.4$ & 0.476 \\
SFA (g) & $30.2 \pm 2.5$ & $24.6 \pm 2.7$ & $36.5 \pm 4.0$ & $\mathbf{0 . 0 1 1}$ \\
MUFA (g) & $29.0 \pm 1.9$ & $23.9 \pm 2.0$ & $34.8 \pm 2.6$ & $\mathbf{0 . 0 0 2}$ \\
PUFA (g) & $12.4 \pm 0.9$ & $11.0 \pm 1.1$ & $13.9 \pm 1.5$ & 0.107 \\
Total n-3 FA (g) & $1.2 \pm 0.2$ & $1.0 \pm 0.2$ & $1.4 \pm 0.4$ & 0.325 \\
Total n-6 FA (g) & $5.8 \pm 0.7$ & $6.3 \pm 1.0$ & $5.3 \pm 1.0$ & 0.458 \\
Trans fats (g) & $1.1 \pm 0.1$ & $1.0 \pm 0.2$ & $1.1 \pm 0.1$ & 0.584 \\
\hline
\end{tabular}

Data are expressed as mean \pm SEM, obtained from self-reported 4-day food diaries

SFA saturated fatty acids, MUFA monounsaturated fatty acids, PUFA polyunsaturated fatty acids, $n-3 F A$ omega- 3 fatty acids, $n-6$ FA omega- 6 fatty acids

${ }^{a} p<0.05$ in bold indicates significant difference between women and men, by Student's $t$ test with DHA and $\mathrm{n} 3$ fatty acids. Concentrations of NAPEs in ileal fluids were positively associated with plasma EPA and DPA. All the correlations found are shown in Supplementary Table 5.

\section{Discussion}

The implications of the endocannabinoid system and its role in human health have become an area of increasing 
interest over the last decade [5]. To date, only a limited number of studies have actually measured ECs, NAEs and NAPEs in human biological fluids with circulating ECs reported in the range $0.2-9.4 \mathrm{ng} / \mathrm{mL}$ (12 studies), NAEs ranging $0.5-64.6 \mathrm{ng} / \mathrm{mL}$ (10 studies), and NAPEs ranging $120.7-800.0 \mathrm{ng} / \mathrm{mL}$ (2 studies) [29, 33, 34, 48-50]. While ECs are acknowledged key mediators in the interplay between gut, microbiota and metabolic health, to the best of our knowledge, their levels and those of NAEs and NAPEs in the gastro-intestinal tract are largely unknown with only one recent human study reporting fecal concentration for single NAPE [51]. In this study, for the first time, the concentrations of ECs, NAEs and NAPEs within the GIT are measured, via ileal fluid, revealing the amount of the compounds that would be colon-available upon leaving the small intestine. We determined that ileal NAEs and particularly OEA $(383.72 \pm 88.78 \mathrm{ng} / \mathrm{mL})$, LEA $(2360.10 \pm 454.74 \mathrm{ng} / \mathrm{mL})$ and PEA $(377.72 \pm 26.08 \mathrm{ng} /$ $\mathrm{mL}$ ) were on average 1.5-13 times higher than that required to elicit a physiological response through the intestinal receptors. Indeed, the agonist activity (EC50) of such compounds on GPR119 ranges from $65 \mathrm{ng} / \mathrm{mL}$ to $1.0 \mu \mathrm{g} / \mathrm{mL}$ for OEA, $180 \mathrm{ng} / \mathrm{mL}$ for LEA and $250 \mathrm{ng} / \mathrm{mL}$ for PEA [52, 53]; OEA also displayed agonist activity on PPAR- $\alpha$ with an EC50 of $39 \mathrm{ng} / \mathrm{mL}$ [15].

In the present study, ileal samples were collected from stoma bags filled during the overnight fasting period and consequently may contain some food residues from the last meal consumed by the participants prior to the fasting period. Therefore, food eaten in that meal might have directly influenced the lipid type and amount in ileal fluids whose composition is more susceptible to individual digestion rate than fasting plasma samples. This may explain the differences in the lipids' profiles between ileal fluids and plasma and why, for example, LEA is the most abundant NAE in the ileal samples while it is the less abundant in plasma. Indeed, we hypothesize that dietary NAEs and NAPEs [35] may result from digestive processes in the proximal GIT following mastication [36, 37], being into the alimentary canal postprandially at concentrations even higher than those found in this study. Such an effect could trigger GLP-1 secretion by enterocytes through activation of intestinal GPR119, thus contributing to the homeostatic regulation of food intake, which is consistent with the findings from Chen and co-workers [54] showing that feeding mice with NAPE-synthesizing bacteria increased delivery of NAEs/NAPEs in the intestinal lumen and significantly reduced food intake and adiposity induced by a high-fat diet. In the case of intestinal NAPEs, their activity necessitates conversion into NAEs through the action of intestinal NAPE-hydrolyzing phospholipase D [55]. NAEs and NAPEs, therefore, appear to be more effective in eliciting a leptogenic effect from the intestinal lumen than in other tissues. Consequently, more robustly designed studies are needed to elucidate the physiological relevance of diet-induced increases in intestinal NAEs and NAPEs postprandially.

It should be noted, that correlations between ileal and plasma LEA and OEA with energy and fat intakes concomitant with the sex differences suggested that an individual's diet may influence NAEs intestinal and plasma concentrations. Dosoky and co-workers reported that fecal concentrations of NAPEs (NAEs precursors) in mice fed with a plant-based diet were significantly higher than in mice fed a lard-based high-fat diet [56], which is in line with our observations that NAPEs are more abundant in plant compared to animal foods [35].

In agreement with Balvers and co-workers, we found that total plasmatic NAPEs were about 13- to 32-fold higher than NAEs [57] and were more abundant in OB than NW and OW. Plasma concentrations of ECs and NAEs in the ileostomy cohort (average BMI $26.9 \pm 0.9$ ) were in the same order of magnitude to those previously measured in overweight and obese subjects with intact GI tracts [19, 28, 29, 32]. In contrast, we did not find any association between 2-AG and AEA with BMI and this is consistent with the reported heterogeneity of observations in the literature, whereby plasma 2-AG has been positively correlated with BMI $[25,26]$ and yet no in other studies $[19,58]$. Similarly, AEA plasma concentrations were elevated in obese subjects compared to normal weight subjects $[19,27,32]$ yet other studies report no association with BMI $[25,26]$.

Other characteristics than BMI which are often disregarded in the populations studied, such as the body composition, the number of women in menopause or the use of drugs or dietary supplements, may be responsible of the different findings between literature studies.

We found sex correlations between the plasma concentrations of AEA, OEA and PEA with individual age and only our observations in women were in agreement with Fanelli et al. [32]. However, serum-free fatty acids were not positively associated with NAEs and AEA in contrast to a previous study in healthy women [59]. The heterogeneity observed is likely due in part to the different age and BMI ranges of the study populations used.

Few studies currently in the literature, reported on whether drugs affected plasma ECs and NAEs other than in relation to treating depression, whereby circulating 2-AG was halved while AEA was unchanged in patients with major depression compared to healthy subjects [60, 61] and antidepressant use did not change plasma EC nor NAE concentrations [61]. In our study, AEA plasma concentrations were about 2- to 4-fold higher than those of depressed patients $[60,61]$, whereas $2-A G$ plasma concentrations were consistent [61] or $\sim 15$-fold lower than patients with depression [60]. 
Inflammatory status (CRP) was positively correlated with the nutritional status as assessed by BMI and was consistent with previous studies [62]. On the other hand, the positive association we found between plasma concentrations of PEA and CRP, independently of BMI, was in agreement with animal and human studies showing that circulating and tissue PEA concentrations increased in subjects suffering from inflammatory diseases, such as neuropathic and inflammatory pain or ulcerative colitis [63]. Furthermore, a recent study reported elevated concentrations of a NAPE, namely 18:1/16:1/18:0, in the faeces of patients suffering from ulcerative colitis in comparison to healthy controls [51].

This study has some limitations. Firstly, the habitual diet and physical activity energy expenditure were estimated by self-reported data from participants using previously validated survey instruments, which is not as reliable as direct observations. Second, since we did not measure total energy expenditure, we could not estimate if participants were in energy balance. If subjects were not in energy balance, this might alter the implications of our observations. Finally, the possible presence of residues of the dinner in the ileal fluids makes any attempt to identify the relationships between ileal and plasma content challenging in this study.

In conclusion, we assessed, for the first time, the concentrations of ECs, NAEs and NAPEs present in ileal fluids from participants with ileostomy and, thus, established the amounts likely to be entering the colon in individuals with an intact GIT. Men had higher ileal concentrations of OEA and LEA than women which positively correlated with the self-reported dietary higher energy and fat intake. An ongoing intervention study will address whether the dietary intakes of NAPEs and NAEs affect the concentrations of NAEs in the intestinal lumen postprandially and if they contribute to the homeostatic control of food intake.

Acknowledgements C.G., K.P., acknowledge funding the Western Health and Social Care Trust, and Ulster University. The funders had no role in design, implementation, analysis and interpretation of data in this study. P.V. and C.G. designed the study; K.P., M.S., R.P., R.L., G.O. and C.G. conducted study, R.F. and S.T. performed the analysis of ECs, NAEs and NAPEs in plasma and ileal fluids; S.T. performed statistical analysis; S.T., P.V., K.P., and C.G. wrote the manuscript.

Funding Open access funding provided by Università degli Studi di Napoli Federico II within the CRUI-CARE Agreement. We acknowledge funding from the Western Health and Social Care Trust, and Ulster University. The funders had no role in design, implementation, analysis and interpretation of data in this study. Data described in the manuscript will be made available upon request.

\section{Compliance with ethical standards}

Conflict of interest On behalf of all authors, the corresponding author states that there is no conflict of interest.
Open Access This article is licensed under a Creative Commons Attribution 4.0 International License, which permits use, sharing, adaptation, distribution and reproduction in any medium or format, as long as you give appropriate credit to the original author(s) and the source, provide a link to the Creative Commons licence, and indicate if changes were made. The images or other third party material in this article are included in the article's Creative Commons licence, unless indicated otherwise in a credit line to the material. If material is not included in the article's Creative Commons licence and your intended use is not permitted by statutory regulation or exceeds the permitted use, you will need to obtain permission directly from the copyright holder. To view a copy of this licence, visit http://creativecommons.org/licenses/by/4.0/.

\section{References}

1. Witkamp R (2018) The role of fatty acids and their endocannabinoid-like derivatives in the molecular regulation of appetite. Mol Aspects Med 64:45-67

2. Simon V, Cota D (2017) Mechanisms in endocrinology: endocannabinoids and metabolism: past, present and future. Eur J Endocrinol 176(6):R309-R324

3. Alexander SPH, Christopoulos A, Davenport AP, Kelly E, Marrion NV, Peters JA, Faccenda E, Harding SD, Pawson AJ, Sharman JL, Southan C, Davies JA (2017) The concise guide to PHARMACOLOGY 2017/18: G protein-coupled receptors. Br J Pharmacol 174:S17-S129

4. Wang Y, Balvers M, Hendriks H, Wilpshaar T, van Heek T, Witkamp R, Meijerink J (2017) Docosahexaenoyl serotonin emerges as most potent inhibitor of IL-17 and CCL-20 released by blood mononuclear cells from a series of $\mathrm{N}$-acyl serotonins identified in human intestinal tissue. BBA Mol Cell Biol Lipids 1862:823-831

5. Witkamp R (2016) Fatty acids, endocannabinoids and inflammation. Eur J Pharmacol 785:96-107

6. Fowler CJ, Doherty P, Alexander SP (2017) Endocannabinoid turnover. Adv Pharmacol 80:31-66

7. Bisogno T (2008) Endogenous cannabinoids: structure and metabolism. J Neuroendocrinol 20:1-9

8. Wei BQ, Mikkelsen TS, McKinney MK, Lander ES, Cravatt BF (2006) A second fatty acid amide hydrolase with variable distribution among placental mammals. J Biol Chem 281:36569-36578

9. Izzo AA, Sharkey KA (2010) Cannabinoids and the gut: new developments and emerging concepts. Pharmacol Therapeut 126:21-38

10. Overton HA, Fyfe MCT, Reynet C (2008) GPR119, a novel G protein-coupled receptor target for the treatment of type 2 diabetes and obesity. Br J Pharmacol 153:S76-S81

11. Balvers MGJ, Verhoeckx KCM, Meijerink J, Wortelboer HM, Witkamp RF (2013) Measurement of palmitoylethanolamide and other $N$-acylethanolamines during physiological and pathological conditions. CNS Neurol Disord 12:26-33

12. Hansen HS, Diep TA (2009) $N$-acylethanolamines, anandamide and food intake. Biochem Pharmacol 78:553-560

13. Cheng Y-H, Ho M-S, Huang W-T, Chou Y-T, King K (2015) Modulation of glucagon-like peptide-1 (GLP-1) potency by endocannabinoid-like lipids represents a novel mode of regulating GLP-1 receptor signaling. J Biol Chem 290:14302-14313

14. Lan H, Lin HV, Wang CF, Wright MJ, Xu S, Kang L, Hedrick JA, Kowalski TJ (2012) Agonists at GPR119 mediate secretion of GLP-1 from mouse enteroendocrine cells through glucoseindependent pathways. Br J Pharmacol 165:2799-2807

15. Fu J, Gaetani S, Oveisi F, Verme JL, Serrano A, de Fonseca FR, Rosengarth A, Luecke H, Di Giacomo B, Tarzia G, Piomelli D 
(2003) Oleylethanolamide regulates feeding and body weight through activation of the nuclear receptor PPAR- $\alpha$. Nature 425:90

16. Lo Verme J, Gaetani S, Fu J, Oveisi F, Burton K, Piomelli D (2005) Regulation of food intake by oleoylethanolamide. Cell Mol Life Sci 62:708

17. Piomelli D (2013) A fatty gut feeling. Trends Endocrin Met 24:332-341

18. Di Patrizio NV, Piomelli D (2015) Intestinal lipid-derived signals that sense dietary fat. J Clin Invest 125(3):891-898

19. Little TJ, Cvijanovic N, Di Patrizio NV, Argueta DA, Rayner CK, Feinle-Bisset C, Young RL (2018) Plasma endocannabinoid levels in lean, overweight, and obese humans: relationships to intestinal permeability markers, inflammation, and incretin secretion. Am J Physiol Endocrinol Metab 315:E489-E495

20. Grill M, Högenauer C, Blesl A, Haybaeck J, Golob-Schwarzl N, Ferreirós N, Thomas D, Gurke R, Trötzmüller M, Gallé B et al (2019) Members of the endocannabinoid system are distinctly regulated in inflammatory bowel disease and colorectal cancer. Sci Rep 9:1-13

21. Chelakkot C, Ghim J, Ryu SH (2018) Mechanisms regulating intestinal barrier integrity and its pathological implications. Exp Mol Med 50:1-9

22. Cani PD, Amar J, Iglesias MA, Poggi M, Knauf C, Bastelica D, Neyrinck AM, Fava F, Tuohy KM, Waget A et al (2007) Metabolic endotoxemia initiates obesity and insulin resistance. Diabetes 56:1761-1772

23. de La Serre CB, Ellis CL, Lee J, Hartman AL, Rutledge JC, Raybould HE (2010) Propensity to high-fat diet-induced obesity in rats is associated with changes in the gut microbiota and gut inflammation. Am J Physiol Gastrointest Liver Physiol 299:G440-G448

24. Di Marzo V, Côté M, Matias I, Lemieux I, Arsenault BJ, Cartier A, Piscitelli F, Petrosino S, Alméras N, Després JP (2009) Changes in plasma endocannabinoid levels in viscerally obese men following a 1 year lifestyle modification programme and waist circumference reduction: associations with changes in metabolic risk factors. Diabetologia 52:213

25. Blüher M, Engeli S, Klöting N, Berndt J, Fasshauer M, Bátkai S, Pacher P, Schön MR, Jordan J, Stumvoll M (2006) Dysregulation of the peripheral and adipose tissue endocannabinoid system in human abdominal obesity. Diabetes 55:3053-3060

26. Côté M, Matias I, Lemieux I, Petrosino S, Alméras N, Després JP, Di Marzo V (2007) Circulating endocannabinoid levels, abdominal adiposity and related cardiometabolic risk factors in obese men. Int J Obes 31(4):692-699

27. Engeli S, Böhnke J, Feldpausch M, Gorzelniak K, Janke J, Bátkai S, Pacher P, Harvey-White J, Luft FC, Sharma AM, Jordan J (2005) Activation of the peripheral endocannabinoid system in human obesity. Diabetes 54:2838-2843

28. Matias I, Gatta-Cherifi B, Tabarin A, Clark S, Leste-Lasserre T, Marsicano G et al (2012) Endocannabinoids measurement in human saliva as potential biomarker of obesity. PLoS ONE 7:e42399

29. Sipe JC, Scott TM, Murray S, Harismendy O, Simon GM, Cravatt BF, Waalen J (2010) Biomarkers of endocannabinoid system activation in severe obesity. PLoS ONE 5(1):e8792

30. Matias I, Bisogno T, Di Marzo V (2006) Endogenous cannabinoids in the brain and peripheral tissues: regulation of their levels and control of food intake. Int J Obes 30:S7-S12

31. Silvestri C, Di Marzo V (2013) The endocannabinoid system in energy homeostasis and the etiopathology of metabolic disorders. Cell Metab 17:475-490

32. Fanelli F, Mezzullo M, Repaci A, Belluomo I, Gasparini DI, Di Dalmazi G, Mastroroberto M, Vicennati V, Gambineri A, Pasquali R et al (2018) Profiling plasma $N$-acylethanolamine levels and their ratios as a biomarker of obesity and dysmetabolism. Mol Metab 14:82-94

33. Tischmann L, Drummen M, Gatta-Cherifi B, Raben A, Fogelholm M, Hartmann B, Holst JJ, Matias I, Cota D, Joris PJ et al (2019) Effects of a high-protein/moderate-carbohydrate diet on appetite, gut peptides, and endocannabinoids-a PREVIEW study. Nutrients 11(10):2269

34. Drummen M, Tischmann L, Gatta-Cherifi B, Cota D, Matias I, Raben A, Adam T, Westerterp-Plantenga M (2020) Role of endocannabinoids in energy-balance regulation in participants in the postobese state-a PREVIEW Study. J Clin Endocrinol Metab 105(7):e2511-e2520

35. De Luca L, Ferracane R, Vitaglione P (2019) Food database of $\mathrm{N}$-acyl-phosphatidylethanolamines, $\mathrm{N}$-acylethanolamines and endocannabinoids and daily intake from a Western, a Mediterranean and a vegetarian diet. Food Chem 300:125218

36. Kong X, Ferracane R, De Luca L, Vitaglione P (2016) Salivary concentration of $\mathrm{N}$-acylethanolamines upon food mastication and after meal consumption: Influence of food dietary fiber. Food Res Int 89:186-193

37. Mennella I, Di Monaco R, Balazy A, Ferracane R, Miele NA, Cavella S, Vitaglione P (2018) Salivary endocannabinoids and $\mathrm{N}$-acylethanolamines upon mastication of a semisolid food: implications in fat taste, appetite and food liking. Food Funct 9:476-484

38. Gillum M, Zhang D, Zhang X, Erion D, Jamison R, Choi C, Dong J, Shanabrough M, Duenas H, Frederick D et al (2008) $\mathrm{N}$-acylphosphatidylethanolamine, a gut-derived circulating factor induced by fat ingestion, inhibits food intake. Cell 135:813-824

39. Besson H, Brage S, Jakes RW, Ekelund U, Wareham NJ (2009) Estimating physical activity energy expenditure, sedentary time, and physical activity intensity by self-report in adults. Am J Clin Nutr 91:106-114

40. Karu N, Deng L, Slae M, Guo AC, Sajed T, Huynh H, Wine E, Wishart DS (2018) A review on human fecal metabolomics: methods, applications and the human fecal metabolome database. Anal Chim Acta 1030:1-24

41. McDougall GJ, Conner S, Pereira-Caro G, Gonzalez-Barrio R, Brown EM, Verrall S, Stewart D, Moffet T, Ibars M, Lawther R et al (2014) Tracking (poly) phenol components from raspberries in ileal fluid. J Agric Food Chem 62:7631-7641

42. Gurke R, Thomas D, Schreiber Y, Schäfer SMG, Fleck SC, Geisslinger G, Ferreirós N (2019) Determination of endocannabinoids and endocannabinoid-like substances in human K3EDTA plasma-LC-MS/MS method validation and pre-analytical characteristics. Talanta 204:386-394

43. Bligh EG, Dyer WJ (1959) A rapid method for total lipid extraction and purification. Can J Biochem Physiol 37:911-917

44. Gregory KE, Bird SS, Gross VS, Marur VR, Lazarev AV, Walker WA, Kristal BS (2012) Method development for fecal lipidomics profiling. Anal Chem 85:1114-1123

45. Tremblay AJ, Morrissette H, Gagné JM, Bergeron J, Gagné C, Couture P (2004) Validation of the Friedewald formula for the determination of low-density lipoprotein cholesterol compared with $\beta$-quantification in a large population. Clin Biochem 37:785-790

46. Folch J, Lees M, Stanley GS (1957) A simple method for the isolation and purification of total lipids from animal tissues. J Biol Chem 226:497-509

47. Strain JJ, Davidson PW, Bonham MP, Duffy EM, Stokes-Riner A, Thurston SW, Wallace JMW, Robson PJ, Shamalaye CF, Georger LA et al (2008) Associations of maternal long-chain polyunsaturated fatty acids, methyl mercury, and infant development in the Seychelles Child Development Nutrition Study. Neurotoxicology 29:776-782 
48. Röhrig W, Achenbach S, Deutsch B, Pischetsrieder M (2019) Quantification of 24 circulating endocannabinoids, endocannabinoid-related compounds, and their phospholipid precursors in human plasma by UHPLC-MS/MS. J Lipid Res 60(8):1475-1488

49. Mennella I, Savarese M, Ferracane R, Sacchi R, Vitaglione P (2014) Oleic acid content of a meal promotes oleoylethanolamide response and reduces subsequent energy intake in humans. Food Funct 6(1):203-209

50. Mennella I, Ferracane R, Zucco F, Fogliano V, Vitaglione P (2015) Food liking enhances the plasma response of 2-arachidonoylglycerol and of pancreatic polypeptide upon modified sham feeding in humans. J Nutr 145(9):2169-2175

51. Santoru ML, Piras C, Murgia A, Palmas V, Camboni T, Liggi S, Ibba I, Lai MA, Orrù S, Blois S et al (2017) Cross sectional evaluation of the gut-microbiome metabolome axis in an Italian cohort of IBD patients. Sci Rep 7:9523

52. Hansen KB, Rosenkilde MM, Knop FK, Wellner N, Diep TA, Rehfeld JF, Hansen HS (2011) 2-Oleoyl glycerol is a GPR119 agonist and signals GLP-1 release in humans. J Clin Endocr Metab 96:E1409-E1417

53. Overton HA, Babbs AJ, Doel SM, Fyfe MC, Gardner LS, Griffin G, Jackson HC, Procter MJ, Rasamison CM, Tang-Christensen M et al (2006) Deorphanization of a $G$ protein-coupled receptor for oleoylethanolamide and its use in the discovery of small-molecule hypophagic agents. Cell Metab 3:167-175

54. Chen Z, Zhang Y, Guo L, Dosoky N, de Ferra L, Peters S, Niswender KD, Davies SS (2017) Leptogenic effects of NAPE require activity of NAPE-hydrolyzing phospholipase D. J Lipid Res 58:1624-1635

55. Chen Z, Guo L, Zhang Y, Walzem RL, Pendergast JS, Printz RL, Morris LC, Matafovona E, Stien X, Kang L et al (2014) Incorporation of therapeutically modified bacteria into gut microbiota inhibits obesity. J Clin Invest 124:3391-3406

56. Dosoky NS, Guo L, Chen Z, Feigley AV, Davies SS (2017) Dietary fatty acids control the species of
$N$-acyl-phosphatidylethanolamines synthesized by therapeutically modified bacteria in the intestinal tract. ACS Infect Dis 4:3-13

57. Balvers MG, Wortelboer HM, Witkamp RF, Verhoeckx KC (2013) Liquid chromatography-tandem mass spectrometry analysis of free and esterified fatty acid $N$-acyl ethanolamines in plasma and blood cells. Anal Biochem 434:275-283

58. Jumpertz R, Guijarro A, Pratley RE, Piomelli D, Krakoff J (2011) Central and peripheral endocannabinoids and cognate acylethanolamides in humans: association with race, adiposity, and energy expenditure. J Clin Endocr Metab 96:787-791

59. Joosten MM, Balvers MG, Verhoeckx KC, Hendriks HF, Witkamp RF (2010) Plasma anandamide and other $N$-acylethanolamines are correlated with their corresponding free fatty acid levels under both fasting and non-fasting conditions in women. Nutr Metab $7: 1-6$

60. Hill MN, Miller GE, Carrier EJ, Gorzalka BB, Hillard CJ (2009) Circulating endocannabinoids and $N$-acyl ethanolamines are differentially regulated in major depression and following exposure to social stress. Psychoneuroendocrinology 34:1257-1262

61. Hauer D, Schelling G, Gola H, Campolongo P, Morath J, Roozendaal B, Hamumi G, Karabatsoakis A, Atsak P, Vogeser M, Kolassa IT (2013) Plasma concentrations of endocannabinoids and related primary fatty acid amides in patients with post-traumatic stress disorder. PLoS ONE 8(5):e62741

62. Choi J, Joseph L, Pilote L (2013) Obesity and C-reactive protein in various populations: a systematic review and meta-analysis. Obes Rev 14:232-244

63. Darmani NA, Izzo AA, Degenhardt B, Valenti M, Scaglione G, Capasso R, Sorrentini I, Di Marzo V (2005) Involvement of the cannabimimetic compound, $N$-palmitoyl-ethanolamine, in inflammatory and neuropathic conditions: review of the available pre-clinical data, and first human studies. Neuropharmacology 48:1154-1163 